\title{
Pupillary response of male and female subjects to pupillary difference in male and female picture stimuli ${ }^{\prime}$
}

THOS. M. SIMMS ${ }^{2}$

UNIVERSITY OF TORONTO

On exposure to a series of identical pictures of a young man and a young woman differing only in size of the pupils of the eyes, the eyes of married Ss dilated more to the opposite sex pictures than to the like sex pictures, dilated most to the opposite sex picture with the larger pupils, and dilated least to the like sex picture with the larger pupils. Difficulties with neutral stimuli were noted and an improved method of assessing picture stimuli brightness was described.

Psychological factors have been reported to be potent determinants of the size of the pupil of the eye (Berrien \& Huntingdon, 1943; Davson, 1963; Hess, 1965; Nunnally et al, 1967; Paivio \& Simpson, 1966). Berrien and Huntingdon found dilation of the pupil during deception, Davson, in describing the psychosensory reflex, found dilation during certain emotional states; Nunnally et al found significant effects on pupil size from five types of psychosensory stimulation; Paivio and Simpson reported more dilation of the pupil during attempts to image abstract words than during attempts to image concrete words; while Hess and his collaborators reported that pupillary responses are influenced by the interest value of picture stimuli (Hess \& Polt, 1960; Hess, Seltzer, \& Shllen, 1965), by the process of solving mental arithmetic problems (Hess \& Polt, 1964), and that the size of the pupils in the eyes in a pair of otherwise identical pictures of an attractive young female influenced the preference of men for one picture over the other (Hess, 1965). Hess recently stated that the choice was reflected in pupillary response (Hess, 1966). The present study investigated the pupillary responses of 12 married male and 12 married female Ss to picture stimuli in which, for each figure, only the size of the pupils had been changed.

\section{Method}

The stimuli were prepared from two pictures obtained from a model agency, one of a young man and one of a young woman, each retouched to make two pictures so that in one the pupils of the eyes appeared dilated and in the other the pupils of the eyes appeared constricted. In addition, a neutral picture stimulus was prepared consisting of the numbers from one to five arranged on a gray background. The pictures were then photographed on 35 mm black and white slides exposed and printed at different densities. The slides were examined for equality of brightness by means of a spot photometer. This method eliminated the most obviously unsuitable slides, but presented a substantial problem for further selection. Accordingly, the slides were projected into a studio television camera and the image strength in r.m.s. volts was measured to three significant digits by means of a Hewlett-Packard Distortion Analyzer (HO5-334A). The slides selected in this fashion fell within $2 \%$ of each other in brightness. None of the picture stimuli selected using the spot photometer were finally used.

Each picture stimulus, i.e., a slide of either the young man or the young woman, was paired with a neutral stimulus, i.e., a slide photograph of numbers on a gray background, and the pair was kept together during all the presentations. Although the neutral stimuli were by measurement to three significant digits all equal to each other in brightness, it was felt to be wise to keep the pairs together, insuring that there were no effects due to unperceived differences. The pairs of stimuli were presented in random order, neutral stimulus first, then picture stimulus, by projection on a ground glass screen at the back of a box-like compartment. The Ss were seated at the front of the compartment, heads positioned on a chin rest to keep the distance between the eyes of each $S$ and the screen at $60 \mathrm{~cm}$. A spring driven Bolex $16 \mathrm{~mm}$ movie camera activated at two frames per sec by a cam lobe equipped synchronous electric motor photographed each S's left eye through an opening just below the screen. The camera was mounted on a tripod to minimize conductive sound transmission through the material of the compartment and its support. Further sound masking was provided by a white noise signal fed through earphones. An interval timer controlled the stimulus presentations of $5 \mathrm{sec}$, the interstimulus intervals of $1 \mathrm{sec}$, and a light in the lens of the camera which went on during the interstimulus intervals, overexposing the films to identify them. Illumination during projection was provided by the projector and a $30 \mathrm{~cm}$ fluorescent tube in the compartment. ${ }^{3}$ Eastman Kodak Infrared $16 \mathrm{~mm}$ movie film (ASA 300) was used. To determine pupil size, the film was examined frame by frame on a $15 x$ $15 \mathrm{~cm}$ Craig film editor, and the enlarged pupil diameter was measured by means of a transparent millimeter vernier scale. Only the time necessary to adjust comfortably the earphones, position the S's 
head on the chin rest, and focus the camera was allowed to acclimate the $\mathrm{S}$ to the experimental situation.

The Ss were 12 married couples obtained from a young married couples' club in London, Ontario. Since pupillary response patterns for sexually deviant personalities may be different (Hess, Seltzer, \& Shlien, 1965), it was decided to use married Ss on the premise that their personalities would be less likely to exhibit sexual deviancies than would a more random sample. All were able to see the projected images without glasses and were processed in chance order. Each $S$ was exposed to a $5 \mathrm{sec}$ presentation of a neutral slide, thus yielding 10 frames of exposed film, followed after a 1 sec interval by a 5 sec presentation of its matched picture slide, affording thereby a within $S$ control for each picture. Then for another pair of slides, the sequence was repeated until all eight slides had been viewed. No instructions concerning what was to be seen were given during the experiment, although the Ss had been told beforehand their eyes were to be filmed as they looked at a series of pictures.

\section{Results}

For each S, diameters for each frame of film for each exposure of the stimuli were plotted for each stimulus, both control and picture, and summed. The difference between the sum of the responses to the control and the sum of responses to its matching picture was calculated.

Three analyses of variance were computed, one for the responses to the control slides, one for the responses to the picture slides, and one for the difference between the responses to each control slide and its matching picture slide. A 2 by 2 by 2 fixed effects model was used, the possible fourth factor eliminated by having randomized the order of presentation of the stimuli. The factors considered were sex of $S$, sex of the picture, and condition of the picture, i.e., whether the pupils were dilated or constricted.

It was intended to analyze only the differences between the responses to the control slides and their matching picture stimuli, but a chance remark prompted the researcher to analyze the data further. One of the Ss indicated he had added the numbers on the control slide. Later questioning revealed that several more had done the same. Since it is reported that the process of solving mental arithmetic problems causes dilation of the pupil (Hess \& Polt, 1964), this effect might exist among the responses to the control slides. These responses were treated as if they were their matching picture slides and subjected to the same analysis. The three factor interaction approached significance $(F=3.33, d f=1 /$ $88, \mathrm{p}<.10)$. The mean of responses to the second presentation of the control stimulus was also calculated. The difference between it and the grand mean of responses was large enough $(t=1.29$, df
$=1 / 88, p<.10$ ) to account for the significance of the three factor interaction being as large as it was.

In the analysis of responses to the picture stimuli, the factor condition of the picture, i.e., pupil size, approached significance $(F=3.03, d f=1 / 88, p<.10)$; the interaction of the factors sex of the picture, and sex of the $S$ was substantially significant ( $F$ $=115.7, \mathrm{df}=1 / 88, \mathrm{p}<.005)$; and the interaction of all the factors was significant $(F=7.09, d f=1 / 88, p$ $<.01)$. None of the other factors or interactions indicated significance.

The analysis of the differences between the responses to the picture stimuli and matching control stimull indicated that interaction of the factors sex of the picture and condition of the picture approached significance $(F=3.29, \mathrm{df}=1 / 88, \mathrm{p}<.10)$, interaction of the factors sex of the picture and sex of the $S$ was highly significant ( $F=40.2, \mathrm{df}=1 / 88, \mathrm{p}<.01$ ), while interaction of all three factors was less but still significant $(F=4.30, \mathrm{df}=1 / 88, \mathrm{p}<.05)$.

\section{Discussion}

The existence of third order interactions in the responses to the control stimuli casts serious doubt on the neutrality of their effect. The fact that dilation was greatest to the second presentation of the control slide suggests further study is needed. The doubt also suggests that conclusions drawn from the analysis of the differences between the responses to the control and picture stimuli might be unreliable. Since the light brightness of the picture stimuli did not vary more than $2 \%$, the responses to these stimuli could provide useful information.

In the responses to the pictures, the near significance $(F=3.03, d f=1 / 88, p<.10)$ of condition of the picture, i.e., either pupils dilated or constricted, suggests there is a bias due to the sex of the $S$ on the sex of the picture since otherwise the responses of one sex should cancel the responses of the other sex. Examination of means in the significant $(F=7.09$, $\mathrm{df}=1 / 88, \mathrm{p}<.01$ ) interaction of the three factors bore this out. The mean response of male Ss to the dilated pupil female picture differs from the mean response of female Ss to the dilated pupil male picture. The mean responses of the two sexes to the constricted pupil opposite sex picture are quite close, but differ in the direction of the indicated bias.

Examination of the mean responses in the highly significant $(F=115.7, \mathrm{df}=1 / 88, \mathrm{p}<.005)$ sex of the picture by sex of the $S$ interaction suggests that $S s$ dilate strongly to opposite sex pictures and substantially less to like sex pictures. The responses of both sexes to like sex stimuli were quite close, but the responses to opposite sex stimuli differed enough to suggest that women dilate less to men than men to women. This was borne out in examination of the means in the third order interaction.

The pattern of mean responses in the significant three factor interaction suggests that Ss dilate most 


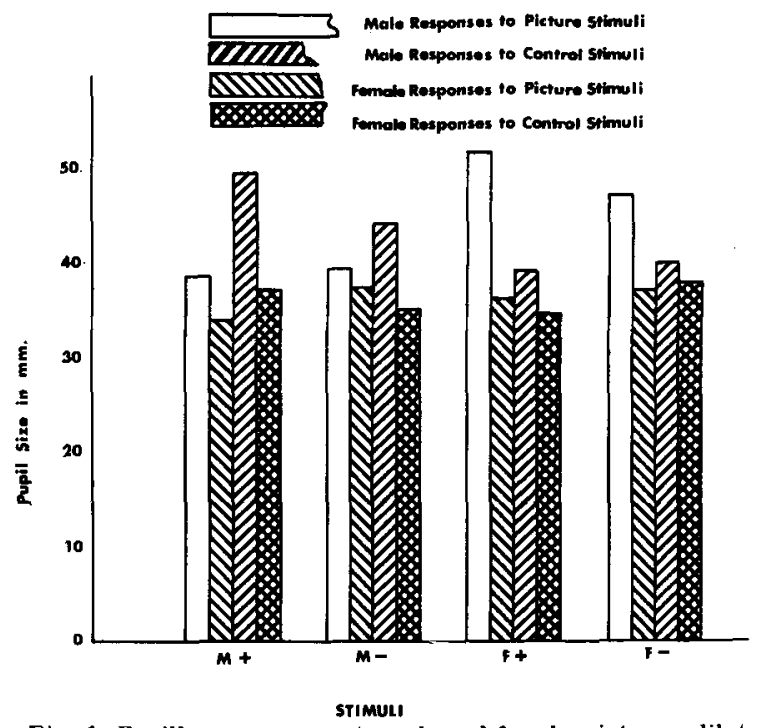

Fig. 1. Pupillary responses to male and female pictures, dilated $(+)$ and constricted $(-)$, and to their control stimuli.

to dilated pupil, opposite sex pictures and least to dilated pupil, like sex pictures. The constricted pupil, opposite sex picture mean response is for both sexes greater than the constricted pupil, like sex picture mean response. Hess suggested that larger pupil diameters implied greater interest (Hess, 1965; Hess \& Polt, 1960). The results of this study suggest that married Ss find opposite sex pictures more interesting than like sex pictures. What is more to the point is that the Ss find the opposite sex picture with large pupils more interesting than the opposite sex picture with small pupils and that the opposite was true for the like sex pictures, i.e., the large pupil, like sex picture was less interesting than the small pupil, like sex picture (see Fig. 1).

The differences of responses to the picture and control stimuli, even though their reliability is somewhat suspect, confirm the main conclusions concerning the pattern of responses due to sex of the picture and the interaction between sex of the picture and the condition of the picture. The analysis of the difference of responses does not confirm any effect due to condition of the picture, but indicates there is an effect in the interaction of the sex of the picture and condition of the picture $(F=3.29$, $\mathrm{df}=1 / 88, p<.10)$. These discrepancies from the picture stimuli effects may well be caused by cognitive reaction to the control stimull not being truly randomly distributed.

It should be further noted that the mean response to the control stimuli is substantially less than the mean response to the picture stimuli. In fact, none of the mean responses to any of the four picture stimuli is less than the mean control response (see Fig. 1). Any conclusive findings, however, must await further study concerning the neutral response. Also, it may be asked if the pupillary response pat- tern is reflected in the stated interest of the Ss, if this response pattern and stated interest is sex linked or interest linked, if the pattern differs for different age groups, or if the pattern would change with a wider variety of picture stimuli.

\section{Summary}

The pupils of the eyes of 12 pairs of married Ss dilated significantly more to opposite sex picture stimuli than to like sex picture stimuli. Further, the Ss exhibited greater responses to the opposite sex picture stimulus with dilated pupils than to the one with constricted pupils. Also, the Ss exhibited larger responses to the like sex picture stimulus with constricted pupils than to the one with dilated pupils. This seems to imply that the Ss preferred or were more interested in the opposite sex, large pupil picture, followed by the opposite sex, small pupil picture, the like sex, small pupil picture, and least of all the like sex, large pupil picture.

Effects due to lack of neutrality of the control stimulus were noted, and their influence on any conclusions drawn from a study of the difference between the response to the control and picture stimuli examined. A more precise method of evaluating slide brightness was reported, enabling the picture stimuli responses to be used without reference to the control stimuli. Possibilities concerning further studies were noted.

\section{References}

Berrien, F. K., \& Huntingdon, G. H. An exploratory study of pupillary responses during deception. J. exp. Psychol., 1943, $32,443-449$.

Davson, H. The physiology of the eye. London: J. \& A. Churchill, 1963.

Hess, E. H. Attitude and pupil size. Scient. American, 1965, 212. 46-54.

Hess, E. H. Personal communication, 1966.

Hess, E. H., \& Polt, J. M. Pupil size as related to interest value of visual stimuli, Science, $1960,132,349-350$.

Hess, E. H., \& Polt, J. M. Pupil size in relation to mental activity during simple problem solving. Science, 1964, 143, 1190-1192.

Hess, E. H., Seltzer, A. L., \& Shlien, J. M. Pupil response of hetero- and homosexual males to pictures of men and women: a pilot study. J. abnorm. Psychol., 1965, 70, 165-168.

Nunnally, J. C., Knott, P. D., Duchnowski, A., \& Parker, R. Pupillary response as a general measure of activation. Percept. \& Psychophys., 1967, 2, 149-155.

Paivio, A., \& Simpson, H. M. The effect of word abstractness and pleasantness on pupil size during an imagery task. Psychon. Sci., 1966, 5, 55-56.

\section{Notes}

1. Summary of a Qualifying Research Project submitted (1966) as part of the requirements for adrnission to candidacy for the degree of Doctor of Education at the University of Toronto, Ontario, Canada.

2. Graduate assistant, Ontario Institute for Studies in Education, 102 Bloor Street West, Toronto 5, Ontario, Canada.

3. The grateful appreciation of the author to the Department of Psychology, University of Western Ontario, London, Ontario, Canada for the use of the preceding equipment is hereby expressed.

(Acceptcd for publication Augrust 1, 1967.) 